\title{
Elisa Kauffman Abramovich: classe, gênero e identidade na vida de uma professora judia e comunista
}

\author{
Elisa Kauffmann Abramovich: class, gender and identity in a jewish and \\ communist teacher's life
}

Guilherme Machado Nunes ${ }^{1}$

\begin{abstract}
Resumo: O presente artigo trata da vida de Elisa Kauffmann Abramovich. Judia descendente de imigrantes do Leste Europeu, Elisa cresceu e se tornou uma importante liderança da comunidade judaica do bairro do Bom Retiro, em São Paulo, atuando em suas associações de assistência social, tornando-se professora e fundando a Escola Israelita Brasileira Scholem Aleichem. Elisa - assim como boa parte dessa comunidade - ingressou no Partido Comunista do Brasil (PCB) entre os anos 1930 e 1940, militando nele até a sua morte em 1963.

Em 1947, Elisa foi eleita a primeira vereadora da história da cidade de São Paulo, e é nosso objetivo compreender como seus diferentes percursos e experiências lhe proporcionaram ocupar esse espaço - mesmo que ela nunca tenha, de fato, tomado posse.
\end{abstract}

Palavras-chave: Biografia; mulheres; comunismo; judaísmo; educação.

\begin{abstract}
This article brings the life of Elisa Kauffmann Abramovich. A descendant of Eastern European Jewish immigrants, Elisa grew up and became an important Jewish community leader in the Bom Retiro neighborhood in São Paulo, working in her social welfare associations, becoming a teacher and founder of the Brazilian Israeli School Scholem Aleichem. Elisa - as well as a good part of this community - joined the Communist Party of Brazil (PCB) between the years 1930 and 1940, militating in it until her death in 1963.

In 1947, Elisa was elected the first councilor in the history of the city of São Paulo, and was separated as her different discoveries and new accomplishments provided the same space - even if she had never actually taken possession.
\end{abstract}

Key words: Biography; women; comunism; judaism; education.

\section{Introdução}

O presente artigo realiza um estudo biográfico sobre Elisa Kauffmann Abramovich, professora judia e militante comunista que atuou em São Paulo

\footnotetext{
${ }^{1}$ Professor visitante no Instituto Federal Catarinense (IFC- Campus Videira). Doutorando em História pela Universidade do Rio Grande do Sul. Integrante do GT Mundos do Trabalho/ Anpuh-RS e o GT História do Marxismo/ Anpuh-RS. e-mail guilherme.mnunes@gmail.com
} 
fundamentalmente entre os anos 1940 e 1950. Filha de imigrantes judeus vindos do Leste Europeu no início do século XX, a família de Elisa em pouco tempo se estabeleceu no bairro paulistano do Bom Retiro, onde foi se constituindo uma comunidade de judeus autointitulados "progressistas": laicos, não-sionistas e com muitas aproximações com o Partido Comunista do Brasil.

Segundo Giovanni Levi, o bom estudo biográfico

\begin{abstract}
Trata-se antes de tudo de um problema de escala e de ponto de vista: se o acento recai sobre o destino de uma personagem - e não sobre o conjunto de uma situação social - a fim de interpretar a rede de relações e obrigações exteriores nas quais ele se insere, é bastante possível conceber de modo diferente a questão do funcionamento efetivo das normas sociais (LEVI, 1996, p. 7).
\end{abstract}

Dessa forma, com Elisa Kauffmanm no centro das ações, podemos conceber de outra forma o funcionamento interno do PCB e as possibilidades de atuação política e social de uma mulher no Brasil dos anos 1940 e 1950. Em um primeiro momento será apresentado o bairro que acolheu Elisa e seus familiares; em seguida será exposta sua militância na juventude e o ingresso nas associações judaicas; a Escola Scholem Aleichem ganhará um item à parte; em seguida, serão abordadas sua militância comunista e a campanha à Câmara de Vereadores em 1947; e por fỉm, as considerações finais.

\title{
O Bairro do Bom Retiro
}

O final do século XIX e início do XX testemunhou um grande fluxo migratório para o Brasil: judeus fugiam dos pogrons patrocinados sistematicamente pelo império russo a partir de 1881. Segundo Erick Zen, o antissemitismo se difundiu nas instituições russas com muita força após o assassinato do Czar Alexandre II pelo grupo Narodnaia Volia. O atentado foi atribuído à judia Hessia Helfman e o czarismo passou a utilizar os pogrons "como forma de dar vazão aos descontentamentos sociais ao incentivar as Centúrias Negras, realizadores dos massacres de judeus mais sangrentos." (ZEN, 2010, p. 35). Um dos destinos que mais recebeu esse grupo de judeus ashkenazim foi a cidade de São Paulo, em especial o bairro do Bom Retiro.

Foi nesse contexto, na década de 1880, que chegaram ao Brasil os "russos" Israel e Anita Kauffman, pais de Elisa. Ele, de Odessa, e ela, da Bessarábia (FILHO, 
2014, p. 19). Segundo uma das netas do casal, Fanny, antes de São Paulo seus avós foram parar em uma cidadezinha chamada Escada, em Pernambuco - local de chegada de muitos judeus no final do século XIX. Elisa e seu irmão Jacob nasceram ali, mas em virtude dos problemas de saúde dele acabaram se mudando para São Paulo. ${ }^{2}$

Provavelmente Israel e Anita perceberam que sua ascendência despertava interesse da polícia brasileira. Segundo a historiadora Zilda Iokoi, tão logo a imigração judaica se tornou volumosa, ocorreu uma espécie de diferenciação de "catalogação" por parte das autoridades nacionais. Judeus do Leste eram vistos como "os mais apegados às suas tradições religiosas e cívicas e constituia-se [sic] por elementos mais dificilmente assimiláveis" (IOKOI, 2004, p. 162), enquanto os ocidentais eram encarados como um "grupo mais assimilável, por terem sofrido os efeitos da civilização ocidental, o que, para os agentes do serviço reservado, significava contar com pessoas mais cultas, cumpridoras e obedientes das leis brasileiras" (IOKOI, 2004, p. 166). Israel e Anita pertenciam ao primeiro grupo.

Em dois momentos posteriores essa situação ganhou novos ingredientes, adquirindo novos significados. O primeiro deles vem com a Revolução Russa de 1917, que somou ao preconceito institucional sofrido pela população judaica advinda do leste a desconfiança e perseguição política oriundas do anticomunismo. O Brasil vivia um momento de ebulição social, com greves e insurreições operárias entre os anos 1917 e 1919, o que levou o Estado a legislar sobre o trabalho ao mesmo tempo em que desenvolvia novos mecanismos de repressão e vigilância - como a expulsão de estrangeiros, a declaração de Estado de Sítio por Arthur Bernardes, em 1922, e a criação do DEOPS de São Paulo, em 1924.

$\mathrm{O}$ segundo momento em que o estigma mudou qualitativamente ocorreu nos anos 1930, com a ascensão do nazifascismo na Europa e posteriormente com o Estado Novo brasileiro. Em 1937, a União da Cultura Judaica (ICUF), entidade mundial de esquerda, decidiu que todas as comunidades judaicas deveriam organizar escolas, jornais, associações culturais, colônias de férias, etc. No Brasil, muitas capitais vão se mobilizar nesse sentido e criar uma enorme gama de associações, cabendo mencionar de antemão algumas dessas entidades que surgiram em São Paulo, como o jornal Nossa Voz. (impresso em português e em iídiche), o Instituto Cultural Israelita Brasileiro

2 Entrevista de Fanny Abramovich a Sara Altman em 20/04/1997, p. 9. Núcleo de História Oral Gaby Becker, AHJB. Mais adiante Fanny afirma que Jacob levou uma vida normal na medida do possível e, embora tivesse muitas dificuldades de locomoção, chegou a ser campeão sul-americano de remo. 
(ICIB/Casa do Povo), a Organização Feminina Israelita de Assistência Social (OFIDAS) e o Colégio (depois Ginásio) Israelita Brasileiro Scholem Aleichem (ALTMAN, 2008, p. 42). Elisa teve destacada atuação em quase todas essas organizações.

Aqui percebemos como o pertencimento étnico, ou até mesmo a noção de identidade de forma mais ampla, não operam no vácuo, apartados da realidade e das diferentes tensões sociais que os rodeiam. O escritor polonês - e judeu - Isaac Deutscher considera que a identidade judaica não está necessariamente atrelada à religião, e que ela aflora em ambientes hostis não-judeus (DEUTSHCER, 1970, p. 4546). ${ }^{3 .}$ Na conjuntura dos anos 1930 e 1940, não apenas a Europa entrava em ebulição com o antissemitismo nazista e a Segunda Guerra Mundial, como no próprio Brasil puderam ser ouvidos ecos desses movimentos históricos. Maria Luíza Tucci Carneiro, por exemplo, mostra como os arroubos do ufanismo antiliberal do Estado Novo se amalgamou com o antissemitismo (CARNEIRO, 2003, p. 26).

Estudos mais recentes sobre migrações judaicas na América Latina, ao mesmo tempo em que de certa forma endossam essa noção da etnicidade se (re)construindo em oposição a outras mais essencialistas, questionam até que ponto o antissemitismo desempenhou um papel determinante em tal processo, afirmando-o como apenas parte da história. Em trabalho sobre o judaísmo em São Paulo durante o Estado Novo, Roney Cytrynowicz, por exemplo, afirma que discursos eram muito mais frequentes do que ações práticas. Assim,

os anos 1937 a 1945 foram de intensa vida institucional que permitiu um boom nas atividades e organizações durante e depois da guerra. Esses foram anos de resoluções institucionais e de definição da identidade "judaicobrasileira" (CYTRYNOWICZ, 2008, p. 93). ${ }^{4}$

Embora não se tenha muitas informações acerca da infância de Elisa Kauffmann, foram essas as tensões que fortaleceram os laços étnicos da comunidade do Bom Retiro

3 Michael Hall, estudando os italianos em São Paulo, sugere que a noção de pertencimento étnico deva ser interpretada tal qual Thompson tratou o conceito de consciência de classe: "em vez de considerála como sempre igual e como uma entidade reificada que determina certas práticas, poderíamos tentar ver, no decorrer das lutas, como uma identificação étnica pode emergir (ou não), se desenvolver e esvaecer em circunstâncias históricas específicas" (HALL, 2010, p. 63).

4 Tradução minha, no original: "Given the divergence between the virulence of discursive antiSemitism and the lack of anti-Semitic attacks, one should not be surprised that between 1937 and 1945 the Jewish minority in São Paulo experienced a vibrant public, institutional, social, cultural, and economic life that would not be expected if one only looks at state memos or the publications of a small circle of antiSemitic elites or the reports of the political police during those years. In fact, 1937 to 1945 were years of intense institutional life that allowed a boom in activities and organizations during and after the war. These were times of institutional settlement and of defning a 'JewishBrazilian' identity". 
onde ela cresceu. Sua militância, tudo indica, teve início no movimento secundarista, logo no golpe do Estado Novo, momento em que, ainda segundo Cytrynowicz, os membros das comunidades judaicas do Brasil passaram a se identificar como "judaicobrasileiros", e não mais como imigrantes ou estrangeiros. Segundo o jornal Nossa Voz, Elisa articulou as lutas pela democracia e as causas judaicas: ocupou a secretaria da Associação dos Estudantes Israelitas e a vice-presidência da Federação dos Estudantes Secundários de São Paulo. ${ }^{5}$

Foi também nessa época que sua mãe aceitou esconder na casa em que moravam o filho de uma amiga, perseguido pelo Estado Novo (FILHO, 2014, p. 19). Segundo relato de Fanny, foi esse rapaz, médico, que recrutou Elisa para o PCB: "Então, esse médico que a minha mãe me contou que nutriu uma paixão avassaladora por ela, e eu não duvido a mínima, e fez a cabeça e ela entrou no partido". ${ }^{6}$

Será que, mesmo com todo o entorno e criação nessa comunidade com fortes laços com as ideias comunistas, foi preciso alguém de fora (um homem!) de seu convívio nuclear para convencê-la a entrar no PCB? Teria sido o seu ingresso uma resposta a um flerte da juventude, ao encantamento que aquele homem despertava? Ou será que essa foi a forma como Elisa lembrava desse momento fundamental de sua trajetória? De qualquer forma, cabe mencionar que seu irmão, Jacob, também foi recrutado pelo Dr. Huck (FILHO, 2014, p. 19).

Contudo, não foi com esse homem que Elisa se casou, mas sim com um comerciante argentino, que com apenas um ano de idade se mudou para o Brasil, chamado Francisco Abramovich. Francisco era filho de Bertha e Nicolau, trabalhador portuário em Odessa e com histórico de militância no Bund, partido socialista judaico (IOKOI, 2004, p. 261). ${ }^{7}$ Bertha e Nicolau fizeram uma das rotas sugeridas pela Jewish Colonization Assossiation (ICA) ${ }^{8}$ : em 1910 partiram para a Argentina, onde em 1914

5 Nossa Voz, São Paulo, 23 de outubro de 1947, p. 2. Hemeroteca Digital Luso-Brasileira (HDB/BN). Esse é o periódico oficial da comunidade judaica progressista e será melhor abordado mais adiante.

6 Entrevista de Fanny Abramovich a Sara Altman em 20/04/1997, p. 13-14. Núcleo de História Oral Gaby Becker, AHJB.

7 O Bund foi um dos principais fundadores do Partido Social-Democrata Operário da Rússia, Lituânia e Polônia e até 1905 foi a maior organização deste tipo no leste europeu. Ver WIAZOVSKI, 2008.

8 Segundo o site do AHJB: “A Jewish Colonization Association foi fundada em 1891 pelo Barão Hirsh com a finalidade de prestar assistência a imigrantes judeus que tinham a premência de emigrar de seus países de origem, em especial da Europa Oriental (onde geralmente eram oprimidos ou perseguidos), para países com melhores oportunidades de vida. [...] Inicialmente os principais destinos dos imigrantes auxiliados pela JCA eram a Palestina e Argentina. Essa última, que contou com uma boa aceitação por parte do governo local, constituiu-se no objetivo final de judeus provenientes de diversos países. A JCA também passou a atuar no Brasil, tornando-se conhecida como ICA [...]". http://www.ahjb.org.br/ahjb_pagina.php?ap=ica Acesso em 12 na 2019. 
tiveram Francisco, na cidade de Santa Fé. ${ }^{9}$ Um ano depois foram para a Bahia e em seguida para Itapira, no interior de São Paulo. ${ }^{10}$

Francisco Abramovich lembra que a tendência progressista sempre estivera presente em sua casa, tendo participado desde muito cedo do Centro Cultura e Progresso e da Casa do Povo, atuando fundamentalmente nas partes mais burocráticas, como secretário. ${ }^{11}$ Segundo sua primogênita, Fanny, foi justamente em uma dessas associações que Francisco e Elisa se conheceram. ${ }^{12}$

Em plena Segunda Guerra Mundial, em março de 1940, Elisa, então com 20 anos, e Francisco, então com 25, casaram-se - seis meses depois nasceu Fanny. É bem provável que ambos estivessem empenhados no Comitê Mrs. Churchill de auxílio às vítimas de guerra, atuante durante todo o conflito bélico. ${ }^{13}$

Segundo Zilda Iokoi (2004, p. 332), as mulheres se envolveram com empenho nesse comitê - o que não causa nenhuma surpresa, afinal a ideia difundida e aceita naquela época da caridade como algo inerente ao feminino e à maternidade acabou por proporcionar uma importante arena de participação pública, especialmente para as mulheres das camadas médias. Sendo Elisa uma jovem com militância estudantil e possível filiação comunista quando da eclosão do conflito, não causaria estranheza que ela tenha se engajado em tal empreitada - o que de fato ocorreu. ${ }^{14}$

O casal conquistou rapidamente grande proeminência na comunidade do Bom Retiro, militando e ocupando importantes cargos em diferentes associações que começaram a surgir no pós-Guerra. É sobre atuação de Elisa nesses espaços que contarão as próximas linhas.

\section{As Associações Judaicas}

9 Entrevista de Fanny Abramovich a Sara Altman em 20/04/1997, p. 6. Núcleo de História Oral Gaby Becker, AHJB.

10 Vale mencionar que essa trajetória é praticamente idêntica à da família da Jacob Gorender, militante comunista, fundador do PCBR (Partido Comunista Brasileiro Revolucionário, um dos tantos rachas do PCB no pós-Golpe de 64) e historiador. Ver IOKOI, 2004 e QUADROS, 2015.

11 Entrevista de Francisco Abramovich a Frida Grinspun e Sara Fridman em 21/09/2000, p. 1. Projeto Memória ICIB, Casa do Povo. Mais adiante veremos que Francisco seguiu exercendo esse tipo de função ao longo de seu casamento com Elisa.

12 Entrevista de Fanny Abramovich a Sara Altman em 20/04/1997, p. 14 Núcleo de História Oral Gaby Becker, AHJB.

13 Entrevista de Francisco Abramovich a Frida Grinspun e Sara Fridman em 21/09/2000, p. 1-2. Projeto Memória ICIB, Casa do Povo.

14 Cf. Nossa Voz, São Paulo, 23 de outubro de 1947, p. 2. Hemeroteca Digital Luso-Brasileira. 
No dia 10 de junho de 1940, fundiram-se três entidades israelitas na cidade de São Paulo. Da união da Gota de Leite B'nai Brith, da Sociedade Beneficente de Damas Israelitas e do Lar da Criança Israelita nasceu a Organização Feminina Israelita de Assistência Social, a OFIDAS. ${ }^{15}$ Visando à assistência de mulheres e crianças necessitadas, a Organização estruturava-se em sete departamentos: Higiene Infantil, Lar da Criança, Orientação Educacional e Profissional, Peah (incumbido de recolher e reparar móveis e roupas usadas), Assistência Social, Gabinete Dentário e Administração. ${ }^{16}$

O primeiro registro encontrado da participação de Elisa nessa entidade remete ao ano de 1942. No dia 9 de fevereiro, em assembleia geral extraordinária da OFIDAS, foi realizada uma reforma nos estatutos da entidade e a eleição de uma nova diretoria, e dentre as assinaturas ao final da ata encontra-se o nome de Elisa. ${ }^{17}$ Com 23 anos de idade, ela possuía apenas um curso profissionalizante de confecção de flores artificiais (FILHO, 2014, p. 22) e teve na OFIDAS a porta de entrada para novas atividades profissionais. Pode-se dizer que seu ingresso na Organização contribuiu significativamente para o alargamento do seu campo de possibilidades (VELHO, 1999), pois, segundo sua filha, foi ali que Elisa "virou uma espécie de professoras de trabalhos manuais", atuando "em um curso que eles tinham para jovens, adolescentes de formação, de habilitação profissional, essa coisa toda, mas a inquietude dela era tão grande que ela foi crescendo e logo não era mais professora, era orientadora, e etc. e tal." 18

Até esse momento, percebe-se que a coletividade judaica de São Paulo se organizava basicamente em torno de pautas de assistência e em defesa das vítimas da Segunda Guerra: ajuda a órfãos e esposas que perderam seus maridos, auxílio a novos imigrantes, etc. Thea Joffe, que trabalhou com Elisa na OFIDAS nesse período, recorda

15 Ata do dia 10 de junho de 1940. Livro de Atas da OFIDAS, p. 1-3. AHJB. Acervo OFIDAS, Caixa 1. Aqui cabe mencionar a presença maciça na assembleia de fundação e na ocupação de cargos diretivos de mulheres de uma família rica, influente e não alinhada com a corrente progressista: a presidência ficou a cargo de Luíza Klabin e a vice-presidência com Fanny Klabin (mãe da mecenas e colecionadora de arte Eva Klabin, que dá nome a um instituto e museu responsável por salvaguardar e expor o acervo adquirido ao longo de sua vida). Assinaram a ata, ainda, Alice Klabin e [ilegível] Klabin.

16 Correspondência à United Hias Service. AHJB. Acervo OFIDAS, Caixa 1.

17 Ata do dia 9 de fevereiro de 1942. Livro de Atas da OFIDAS, p. 6. AHJB. Acervo Ofidas, Caixa 1.

18 Entrevista de Fanny Abramovich a Sara Altman em 20/04/1997, p. 9. Núcleo de História Oral Gaby Becker, AHJB. 
que a amiga era responsável por arrumar escolas, empregos, médicos e moradia para os recém-chegados. ${ }^{19}$

Quando os ventos democráticos parecem soprar com mais força da Europa, começa a se engendrar um esforço coletivo para pôr em prática o que o ICUF pregava desde 1937: a proliferação de entidades judaicas propositivas, garantindo a disseminação e preservação da cultura judaica através de centros, associações, escolas, etc. Em São Paulo, o ponto fundamental dessa "virada" ocorreu com a construção da Casa do Povo, sede do Instituto Cultural Israelita Brasileiro, em 1946. Segundo Marcos Ajzenberg (2008, p. 34-35), o lugar foi construído por um "grande capitalista judeu" chamado Manuel Casoy, que prometeu que doaria os fundos assim que o Exército Vermelho conquistasse Berlim. Esse lugar, localizado na Rua Três Rios, 252 - e ainda hoje de pé - passou a ser uma espécie de polo aglutinador das agremiações judaicas progressistas a partir de então, de onde irradiavam e para onde convergiam os mais diversos esforços organizativos.

No final de 1947 Elisa era a diretora do curso vocacional da OFIDAS. ${ }^{20}$ Não constitui novidade alguma na história brasileira o fato de atividades ligadas à educação e ao magistério constituírem uma oportunidade de ingresso e ascensão no mercado de trabalho para as mulheres. Guacira Lopes Louro identifica no início do século XX um processo que ela chamou de "feminização do magistério", calcado em um discurso que emergia na época, segundo o qual "as mulheres tinham, 'por natureza', uma inclinação para o trato com as crianças, que elas eram as primeiras e 'naturais educadoras', portanto nada mais adequado do que lhes confiar a educação escolar dos pequenos" (LOURO, 1997, p. 450).

Notícias sobre Elisa surgiam com maior frequência, e ela aparecia cada vez mais como uma liderança comunitária em ascensão. O primeiro semestre de 1949 trouxe a festa de aniversário de 10 anos da OFIDAS, e coube a Elisa a fala em nome da diretoria. $^{21}$

O ano de 1949 também trouxe tensões àquela comunidade. Quanto mais o tempo passava, mais polêmica se tornava a questão acerca do Estado de Israel.No final dos anos 1940 houve um paulatino rompimento entre a esquerda e a direita judaicas (cf.

19 Entrevista de Fanny Abramovich a Sara Altman em 20/04/1997, p. 23. Núcleo de História Oral Gaby Becker, AHJB. Há trabalhos que mostram organizações muito semelhantes atuando também entre a comunidade judaica argentina (ver GUY, 2008).

20 São Paulo, 24 de dezembro de 1947, n. 39, p. 8. BDLB. Acesso em 12/07/2017.

21 Nossa Voz, São Paulo, 5 de maio de 1949, n. 110, p. 8. BDLB, acesso em 16 abr 2017. 
IOKOI, 2004, p. 153), e isso se fez sentir inclusive nas associações sem posicionamentos políticos declarados. Tanto é assim que, ao publicar suas diretrizes e princípios no jornal Nossas Voz, a OFIDAS fez questão de frisar que não era sionista nem anti-sionista. ${ }^{22}$

Na noite de 9 de agosto de 1951, Elisa participou - inclusive secretariou os trabalhos - de uma tensa e extraordinária assembleia geral da OFIDAS, que só deveria ocorrer em setembro de 1952. Parte da diretoria identifica na questão sionista um ponto importante de inflexão na participação e efetividades das ações da OFIDAS, que encontravam-se em crise. Para formar a chapa responsável por renovar a Organização, a diretoria "entrou em contato com figuras de destaque na coletividade", que não foram recebidas com unanimidade pelo quórum. Elisa, se não estava oficialmente na diretoria anterior, certamente estava muito próxima, pois dirigia importantes iniciativas da OFIDAS e foi secretária dessa reunião. Agora seu nome não constava nos quadros diretivos. ${ }^{23}$ Aliás, não foram encontradas suas assinaturas nas atas de reunião até o mês de maio de 1960, o que indica uma menor participação dela na entidade.

Isso não significa dizer que Elisa tenha se afastado da "coletividade". A OFIDAS representou uma oportunidade prática de formar-se enquanto educadora e assistente social, ambas atividades associadas às mulheres, em uma época em que a educação formal era bem menos acessível do que hoje. Ana Paula Vosne Martins (2015, p. 23) mostra como desde o final do século ocorreu um processo de "feminilização da filantropia", especialmente entre mulheres das camadas médias e da elite do Ocidente. Para a autora, se por um lado essas práticas se embasavam em discursos movidos por "sentimentos morais e para a caridade cristã",

\begin{abstract}
encontravam ressonância entre as mulheres porque algumas delas perceberam que este poderia ser um caminho promissor para colocarem em prática suas ideias reformistas e, como notaram algumas lideranças femininas da época, pela filantropia as mulheres poderiam ser reconhecidas por sua "utilidade" social.
\end{abstract}

No final dos anos 1940, munida de experiências em novas áreas de atuação, Elisa pôde se dedicar mais especificamente ao trato de crianças - outra forma de atuação pública "aceita" pelos padrões da época e que era reforçada pela "ideologia da domesticidade" (MARTINS, 2015, p. 25). Esse trabalho se deu fundamentalmente 
através de duas formas: na Associação Feminina Vita Kempner e na Escola Scholem Aleichem.

A Associação Vita Kempner surge em São Paulo em 1948 com a finalidade de “ajudar os órfãos judeus necessitados, cujos pais pereceram como mártires e seus filhos, que sobreviveram, estão hoje espalhados pelos países da Europa". ${ }^{24}$ Tratava-se de uma espécie de associação coirmã de uma homônima do Rio de Janeiro, fundada em 1947 (GOLDFELD, 2007, p. 31). ${ }^{25}$ Ambas mudariam o seu nome para Associação Feminina Israelita Brasileira pouco tempo depois, e a seção paulista da Associação contava com Elisa Abramovich na sua primeira diretoria (GOLDFELD, 2007, p. 37).

No final de 1949 a Vita Kempner de São Paulo realizou pela primeira vez uma atividade que se tornaria corrente e talvez seu principal carro-chefe: a "primeira colônia de férias Vita Kempner - para crianças israelitas necessitadas." ${ }^{26}$ Ao longo do ano de 1950 foi possível perceber uma maior organização nos preparativos para a colônia. Entre os dias 18 e 20 de agosto ocorreu o I Congresso Nacional Vita Kempner, no Rio de Janeiro. ${ }^{27}$ A delegação paulista, ao regressar para sua cidade, informou às demais associadas o que foi discutido no Congresso, cabendo destacar aqui alguns dos 17 pontos informados: criação de uma colônia de férias permanente; criação de clubes infantis; fortificação do departamento cultural, ampliando os círculos de leitura; apoio ao apelo de Estocolmo, exigindo a proibição de armas atômicas - uma das grandes bandeiras do PCB no período e do movimento comunista internacional como um todo. Mais importante que isso é constatar que foram formadas comissões para que as resoluções se transformassem em realidade, e à Elisa coube integrar a Comissão de Clubes Infantis. ${ }^{28}$ Para viabilizar a colônia eram necessárias muitas campanhas para angariar doações da comunidade. Logo após esse Congresso, em novembro, é possível perceber que as associadas começaram a realizar o trabalho desde sua casa: tanto a mãe quanto a sogra de Elisa fizeram doações para que a colônia se realizasse. ${ }^{29}$

24 Nossa Voz, São Paulo, 2 de dezembro de 1948, n. 88, p. 8. O curioso é que, ao final da apresentação, a Associação encerra o texto com vivas ao Estado de Israel, evidenciando como o desgaste acerca do debate sionista não foi imediato ao surgimento do dito Estado.

25 Segundo a autora, a associação existe até hoje e a partir de 1988 passou a se chamar Kinderland, por isso é comum encontrar relatos se referindo a ela com esse nome mesmo nos anos 1950.

26 Nossa Voz, São Paulo, 3 de novembro de 1949, n. 136, p. 8. BDLB, acesso em 16 abr 2017.

27 Nossa Voz, São Paulo, 3 de agosto de 1950, n. 175, p. 8. BDLB, acesso em 16 abr 2017.

28 Nossa Voz, São Paulo, 8 de setembro de 1950, n. 180, p. 8. BDLB, acesso em 16 abr 2017. Os círculos de leitura seriam retomados em março de 1955 , incluindo um círculo feminino chamado Anita Garibaldi. Cf. Nossa Voz, São Paulo São Paulo, 11 de março de 1955, n. 512, p. 9. BDLB, acesso em 16 abr 2017.

29 Nossa Voz, São Paulo, 9 de novembro de 1950, n. 189, p. 8. BDLB, acesso em 16 abr 2017. 
No ano seguinte, a colônia se tornava permanente, e a isso somou-se também um novo nome: Kinderland. Seu surgimento foi anunciado no jornal Nossa Voz, que fez um relato sobre essa experiência que contou com 110 crianças provenientes de São Paulo, Rio de Janeiro, Niterói e Belo Horizonte. ${ }^{30}$

A colônia cresceu tanto e tão rapidamente que apenas integrantes da Associação (que agora já se chamava Associação Feminina Israelita Brasileira, AFIB) não poderiam mais dar conta das tarefas a ela associadas, sendo necessária a contratação de monitores para acompanhar os colonistas. Composta por jovens, essa monitoria precisaria ser muito bem treinada para atender às crianças e, a partir de 1953, é possível encontrar chamadas para o curso de monitores. Um ano depois o semanário Nossa Voz trouxe em sua capa a programação do curso na íntegra, e coube a Elisa a pauta "finalidade e organização do trabalho infanto-juvenil". ${ }^{31}$ Esse curso ocorreu em janeiro de 1955, antes do início da colônia, e conforme o jornal, "a infatigável Elisa Abramovich" foi sua grande organizadora. ${ }^{32}$

Para que as crianças mantivessem o contato fora da colônia, foi criado, no ano de 1954, o clube I. L Peretz, ${ }^{33}$ que proporcionaria a essas crianças círculos de leitura, aulas de teatro e outras atividades culturais, e tratou-se de mais uma tarefa realizada por Elisa, pois é importante lembrar que ela fora designada para a Comissão de Clubes Infantis no I Congresso Nacional Vita Kempner quatro anos antes. Francisco Abramovich recorda que, apesar da independência, tanto a AFIB quanto o Clubinho funcionavam na Casa do Povo, o que conferia certa unidade às diferentes associações e borrava suas fronteiras. ${ }^{34}$

Como é possível perceber, todas as instituições da qual Elisa foi parte fundamental se engajaram nessa empreitada, não sendo surpresa, portanto, que o jornal cite ela e Francisco como "dois incansáveis batalhadores” para que o Clubinho seguisse funcionando:

No entanto, mesmo toda a boa vontade de parte das instituições coirmãs e do comitê conjunto não teria possibilitado alcançar o que foi alcançado em prol do desenvolvimento do "Clubinho", se para a direção do mesmo não houvesse sido designados Elisa e Francisco Abramovich.

\footnotetext{
Nossa Voz, São Paulo, 29 de janeiro de 1952, n. 267, p. 8. BDLB, acesso em 16 abr 2017. Nossa Voz, São Paulo, 9 de novembro de 1954, n. 487, p. 1. BDLB, acesso em 18 abr 2017. Nossa Voz, São Paulo, 21 de janeiro de 1955, n. 504, p. 5. BDLB, acesso em 18 abr 2017. Judeu Polonês nascido na metade do século XIX, escritor e autor de peças em iídiche.

Entrevista de Francisco Abramovich a Frida Grinspun e Sara Fridman em 21/09/2000, p. 2. Projeto Memória ICIB, Casa do Povo.
} 
A reconhecida capacidade administrativa do ativo militante cultural e social Francisco Abramovich, aliada à direção pedagógica de Elisa Abramovich. ${ }^{35}$

O jornal também traz relatos das crianças que participaram da festa, e uma delas, de nome Glória, era aluna da escola Scholem Aleichem, fundada por Elisa. ${ }^{36}$

\section{O Scholem Aleichem}

Talvez a criação e a direção da escola sejam os legados de Elisa mais lembrados até os dias de hoje, pois tratou-se de uma experiência de vanguarda na área da educação e formou uma grande quantidade de alunos e alunas ao longo de quase 40 anos. Segundo Fanny Abramovich - e isso em mais de uma entrevista -, foi por tarefa partidária que Elisa assumiu a responsabilidade de fundar uma escola. ${ }^{37}$ Assim, em novembro de 1948, Elisa e uma comissão para criar o Colégio Israelita-Brasileiro Scholem Aleichem realizaram um jantar de angariação de fundos no salão do Palácio Trocadero, ${ }^{38}$ e em janeiro a escola iniciava as matrículas para o ano letivo de 1949, que teria início em fevereiro.

Se em um primeiro momento a fundação da escola pode parecer a aventura de uma disciplinada militante com alguma bagagem na área, uma análise acerca do funcionamento do Scholem evidencia que se tratou de uma experiência ímpar na história da pedagogia brasileira. Além disso, cabe lembrar que sua fundação também atendeu aos anseios e diretrizes propostas em 1937 pelo ICUF, nos mostrando como os diferentes pertencimentos de Elisa se entrecruzaram constantemente.

Uma escola israelita em São Paulo não constituiria, por si só, uma novidade. Porém, como aponta Natália Frizzo de Almeida (2015, p. 15-16), o projeto era diferente pois defendia "o ensino da língua iídiche, em detrimento do hebraico. A partir disso, buscaram empreender 'experimentações educacionais' e inovar em termos metodológicos e nas suas opções curriculares."

35 Nossa Voz, São Paulo, 7 de dezembro de 1961, n. 913, p. 9. BDLB, acesso em 17 abr 2017.

36 Nossa Voz, São Paulo, 7 de dezembro de 1961, n. 913, p. 7. BDLB, acesso em 16 abr 2017.

37 Cf. Entrevista de Fanny Abramovich a Sara Altman em 20/04/1997, p. 14-15. Núcleo de História Oral Gaby Becker, AHJB. É importante mencionar que em 1962, com o afastamento de Elisa da Escola em virtude de sua doença, quem assumiu a direção foi Frima Grinspum, que relata: "na realidade, eu fazia parte da diretoria executiva, devida a toda a história de minha vida, do meu irmão Iacha, que era comunista, filho de comunista e participante do partido e eu vim parar aqui também por isso." Ou seja, havia uma relação íntima entre a militância comunista e a escola. Entrevista com professoras do primário à Tânia Furman e Frima Grinspum em 18/11/2000, p. 10. Projeto Memória ICIB, Casa do Povo.

38 Nossa Voz, São Paulo, 4 de novembro de 1948, n. 84, p. 8. BDLB, acesso em 16 abr 2017. 
Todos os relatos de ex-alunos e profissionais do colégio conferem à Elisa um papel decisivo, destacando-a como organizadora e mentora intelectual do Scholem. A ex-aluna Lilian Starobinas, por exemplo, descreve Elisa da seguinte maneira:

\begin{abstract}
Autodidata, reunia erudição das leituras à confiança no talento dos professores e orientadores que contratava. Apostava numa escola dinâmica, na qual os professores continuavam estudando e eram incentivados a criar. A experiência na militância comunista incitou em Elisa a necessidade de unir teoria e prática, e a direção de uma escola como o Scholem apresentou-se como um terreno fértil para materializar ideias que rompiam com a camisade-força do sistema de educação formal (STAROBINAS, 2008, p. 14).
\end{abstract}

Oficialmente, Elisa foi diretora da escola somente entre 1958 e 1962, mas segundo Fanny isso ocorreu apenas por questões formais, uma vez que ela não possuía formação e/ou tempo de serviço para assinar os diplomas. Fanny recorda, ainda, como se ensinava a cultura judaica sempre em relação com a cultura brasileira: "para mim é muito nítido que se comemorava Pessach não junto com a páscoa, mas junto com Tiradentes, como dois movimentos de libertação, sabe?" (ABRAMOVICH, 2008, p. 16). Segundo o ex-aluno Marcos Ajzenberg, a escola também era conhecida pela sua qualidade, pois "alunos médios da Escola conseguiam facilmente transpor os famosos exames de admissão, conseguindo matricular-se nos melhores ginásios públicos”, algo fundamental "para a ascensão de grande parte da comunidade judaica, cuja segunda geração pôde graduar-se nas universidades brasileiras" (AJZENBERG, 2008, p. 38).

A ex-professora de iídiche, Sara Cunha Lima, recorda que com o tempo houve uma grande quantidade de crianças não-judias matriculadas na escola. Eram basicamente "filhos de intelectuais que queriam a escola mais interessante para os filhos. Os filhos do Guarnieri (Gianfrancesco) estavam aqui... eram os filhos de uma vanguarda." 39 Afinal de contas, quem não gostaria de matricular seus filhos em uma escola que recebia as visitas de Caetano Veloso, Belchior e Novos Baianos (STAROBINAS, 2008, p. 14) e que homenageava Florestan Fernandes em suas formaturas $?^{40}$

39 Entrevista com professoras do primário à Tânia Furman e Frima Grinspum em 18/11/2000, p. 5. Projeto Memória ICIB, Casa do Povo. Em entrevista ao jornal Nossa Voz em 1959, Elisa afirmou: "Temos na Escola um número bastante significativo de crianças não-judias - continua a Sra. Elisa Abramovich - que se têm integrado perfeitamente ao ambiente, participando ativamente de todos os trabalhos e realizações. Estas crianças, inclusive, são ótimas alunas em iídiche.” Nossa Voz, São Paulo, 29 de outubro de 1959, n. 809, p. 9. BDLB, acesso em 17 abr 2017.

40 A Formatura da turma de 1960 homenageou o sociólogo: "O homenageado especial, ou melhor, patrono eleito da turma, era o Prof. Florestan Fernandes, da Faculdade de Filosofia, Ciências e Letras da USP, o qual, tendo embora aceito a homenagem - e tendo inclusive feito uma visita à Escola, da qual saiu encantado - não pôde porém comparecer, por se encontrar, naquela semana, no México, 
É possível apontar fundamentalmente dois diferenciais da gestão e concepção de Elisa sobre o funcionamento do Scholem que explicam seu caráter de vanguarda: a inspiração no pedagogo ucraniano Anton Makarenko (1888-1939) ${ }^{41}$ e o recrutamento e formação de professoras. A professora Cecília da Silveira Luedemann teve acesso aos três volumes de Poema Pedagógico, de Makarenko, com as anotações de Elisa. Segundo ela, seus principais pontos de interesse na obra foram a organização dos educadores, a educação inclusiva, a resolução de conflitos por debates e assembleias e a construção de um futuro baseado na igualdade de direitos e deveres (LUEDEMANN, 2008, p. 77-78).

Para colocar em prática essas ideias, desde a fundação do Scholem Elisa recrutou um grupo de professoras em sua maioria muito jovens, com pouca (ou até nenhuma) experiência em sala de aula e abertas a essa forma de organização e concepção pedagógica. Sua filha Fanny, logo que ingressou no curso de pedagogia da USP, ${ }^{42}$ começou a trabalhar no Scholem. Professora de artes e teatro, ela recorda: "A gente se formou aqui, não veio formada de outro lugar. A gente se fez fazendo." (ABRAMOVICH, 2008, p. 14) O próprio Scholem oferecia cursos de formação.

Praticamente todas as professoras ingressaram na escola pelas mãos de Elisa. Todas mulheres. Elisa não estava imune a ideias fortemente arraigadas na sociedade de seu tempo, como a de que o magistério era um lugar propício para mulheres. Mas é possível também que ela enxergasse no magistério uma boa oportunidade de atuação e crescimento profissional para aquelas jovens assim como havia sido para ela anos atrás. Não há como saber com certeza e uma hipótese não exclui necessariamente a outra, mas de qualquer forma não foram apenas aspectos identitários (judaísmo) e políticos (ideias progressistas) que marcaram a experiência de Elisa no Scholem, mas também de gênero.

A família de Elisa também se fez presente nas instâncias diretivas do Scholem. Além de sua filha Fanny, que lecionou na escola por muito tempo, ${ }^{43}$ Francisco estava na

representando a UNESCO.” Nossa Voz, São Paulo, 19 de janeiro de 1961, n. 871, p. 9. BDLB, acesso em 17 abr 2017.

41 Pedagogo ucraniano que se especializou no trabalho com menores abandonados, especialmente os que viviam nas ruas e estavam associados ao crime e que concebeu um modelo de escola baseado na vida em grupo, na autogestão, no trabalho e na disciplina que contribuiu para a recuperação de jovens infratores. Em suas práticas pedagógicas demonstrou grande habilidade junto às questões educacionais, colocou em prática uma maneira revolucionária e eficaz de educar. Ver https://pt.wikipedia.org/wiki/Anton_Makarenko e https://novaescola.org.br/conteudo/1557/antonmakarenko-o-professor-do-coletivo. Acesso em 14 jan 2019.

42 Nossa Voz, São Paulo, 12 de março de 1959, n. 778, p. 9. BDLB, acesso em 17 abr 2017.

43 Fanny chegou a representar a escola ao lado de sua mãe na Conferência de Escolas Judaicas Progressistas do Brasil organizada pelo Comitê Central da União Cultural Israelita Brasileira, 
direção da Casa do Povo desde 1957, e seu sogro, Nicolau, era membro do conselho fiscal. ${ }^{44}$ Em 1960, passou a integrar também o conselho fiscal da escola, enquanto seu irmão, Jacob, compunha a Comissão Cultural e Social. ${ }^{45}$

Havia algo mais que unia Elisa, seus familiares próximos e boa parte dessa comunidade: a vida no Partido Comunista.

\section{A militância no PCB}

Escrever a história de militantes políticos constitui um grande desafio, e no caso das mulheres, a dificuldade é ainda maior, em virtude da escassez e do caráter das fontes normalmente disponíveis. Como escreveu Michelle Perrot, ou à mulher - de elite ou classe média, acrescento - cabem os espaços domésticos e seus respectivos vestígios (livros de receitas, fotos, cadernos), ou se militante, "tem dificuldade em se fazer ouvir pelos seus camaradas masculinos" (PERROT, 2017, p. 198).

No caso do PCB, em que pese uma ou outra tentativa de articulação feminina desde sua fundação (ver FERREIRA; LINS, 2015), é importante notar que foi somente na III Conferência do PCB, em 1946 no Rio de Janeiro, que em um documento partidário oficial apareceu o termo "mulheres" (cf. MELO; RODRIGUEZ, 2018, p. 102), explicitando no papel essa preocupação e inaugurando no Partido uma nova fase, que visaria abarcar tanto a militância feminina em suas fileiras quanto suas pautas em suas bandeiras. A partir de então surgiram diversos tipos de agremiações de mulheres vinculadas ou simpáticas ao partido, e com isso aumentam seus espaços na imprensa oficial, a publicação de seus textos e a perseguição por parte da repressão, o que facilita a pesquisa.

Questões anteriores ao período de militância e/ou do âmbito privado acabam ficando sujeitas à sorte e à vontade de terceiros em preservar a memória e o legado da pessoa biografada em questão. No caso de Elisa, em que pese haver documentação acerca de sua militância partidária - especialmente na época de sua campanha eleitoral, como veremos adiante - abundam as lacunas, preenchidas a partir de alguns indícios, sobretudo orais e memorialísticos. Segundo Michelle Perrot,

ocorrida nos dias 10 e 11 de agosto na Biblioteca Scholem Aleichem, no Rio. Nossa Voz, São Paulo, 30 de agosto de 1962, n. 948, p. 11. BDLB, acesso em 17 abr 2017.

44 Nossa Voz, São Paulo, 9 de julho de 1957, n. 702, p. 3. BDLB, acesso em 16 abr de 2017.

45 Nossa Voz, São Paulo, 20 de outubro de 1960, n. 858, p. 8. BDLB, acesso em 16 abr de 2017. 
[...] Os modos de registro das mulheres estão ligados à sua condição, ao seu lugar na família e na sociedade. O mesmo ocorre com seu modo de rememoração, de montagem propriamente dita do teatro da memória. Pela força das circunstâncias pelo menos para as mulheres de antigamente, e pelo que resta de antigamente nas mulheres de hoje (e não é pouco), é uma memória do privado voltada para a família e o íntimo, os lugares aos quais elas foram de alguma forma delegadas por convenção ou posição (PERROT, 1989, p. 15).

Podemos ver, de certa forma, como isso opera no relato de Fanny sobre a filiação partidária de sua mãe, por exemplo. Segundo ela, um médico escondido na casa da família teria recrutado tanto Elisa quanto seu irmão Jacob, como mencionado anteriormente, o que indica como a rememoração, mesmo de uma atividade política e pública, tem origem no privado, no seio familiar.

Em termos de documentação e registro público, nem para o aparato repressivo e vigilante brasileiro - em plena atividade durante toda a experiência dita democrática era muito evidente sua data de filiação. Um documento de outubro de 1947 listava todos os candidatos comunistas da sigla do Partido Social Trabalhista, legenda que abrigou quase todas as candidaturas comunistas em São Paulo, visto que o PCB já estava na ilegalidade. Sob o nome de Elisa, um lacônico "Elemento novo no Partido, ainda não registra anotações." ${ }^{46}$ Seu prontuário do DOPS, que data de 5 de novembro de 1947 , também não possui quaisquer anotações. ${ }^{47}$

De qualquer forma, é a partir de sua candidatura à Câmara Municipal em 1947 que se pode acessar mais documentos relacionados a Elisa. Uma vez no pleito, surgem notícias, entrevistas e dados biográficos.

Essa candidatura parece ter sido algo bastante inesperado e decidida de última hora, uma vez que foi apenas no início de outubro que Nossa Voz noticiou o ocorrido em outubro (o pleito seria em novembro), utilizando expressões como "informação de última hora". ${ }^{48}$

$\mathrm{Na}$ apresentação de Elisa ao pleito, de início, é possível perceber como se articulam alguns de seus pertencimentos fundamentais: ser professora e filha de uma família importante daquela comunidade. Na próxima edição do jornal enfatiza-se também o fato de ser mulher:

46 Secretaria de Segurança Pública. Departamento de Ordem Política e Social. Cópia de comunicado/ofício ao Juiz de Direito da Zona Eleitoral de São Paulo, 21 de outubro de 1947, p. 7. APESP. Dossiê Comunismo, OS 1902, Pasta 1.

47 Secretaria de Segurança Pública. Departamento de Ordem Política e Social. Prontuário no 86.162. APESP. Dossiê Comunismo, OS 1902, Pasta 1.

48 Nossa Voz, São Paulo, 9 de outubro de 1947, n. 28, p. 8. BDLB, acesso em 16 abr 2017. 
Como mulher e profissional, conhecedora dos problemas e dificuldades da maternidade e da infância, [Elisa Kauffmann] defenderá ativamente a criação de escolas e creches, postos de saúde e puericultura, para atender principalmente as necessidades da mulher laboriosa. ${ }^{49}$

Elisa se apresentava como uma mulher que defenderia os interesses de suas companheiras, ainda entendidos muito em função do trabalho e da maternidade. Esta era, de maneira geral, uma importante forma de compreensão do tema pelo Partido e pelo movimento comunista internacional - que chegou a organizar um Congresso Mundial de Mães nos anos 1950. A questão se interseccionava com aspectos étnicos e de classe, articulando-se da seguinte maneira: a mulher trabalhadora precisava de boas creches para deixar seus filhos a fim de poder trabalhar e ganhar seu dinheiro, diminuindo a dependência do marido.

Quanto mais se aproximava a eleição, mas essas questões eram misturadas e enaltecidas. Expressões como "Militante democrática", "filha", "mãe”, "esposa" apostos que lhe garantiriam respeitabilidade -, "solidária" "israelita" eram utilizados com frequência. ${ }^{50}$

De certa forma, tudo isso se concentrou e foi sintetizado pelas suas propostas de campanha:

1. Defesa dos interesses da população do Bom Retiro, Luz, Santa Efigênia, Santa Cecília, Vila Buarque e Campos Elísios.

2. Remoção do meretrício, do Bom Retiro para fora do perímetro urbano da cidade, e imediato aumento do policiamento no Bom Retiro e Luz.

3. Barateamento dos gêneros de primeira necessidade e instalação de restaurantes populares, especialmente para a mulher laboriosa, na Rua José Paulino.

4. Loteamento de terrenos a serem vendidos a longo prazo e prestações módicas, para edificação de modernas habitações populares no lugar dos cortiços e favelas.

5. Aumento e Barateamento dos meios de transporte.

6. Calçamento e canalização do "Baixo Bom Retiro".

7. Instalação de novas escolas, de escolas mistas brasileiras-israelitas, de creches, postos de saúde e puericultura.

8. Instalação no Jardim da Luz, na Praça Princesa Isabel e no Largo Coração de Jesus, de parques infantis.

9. Organização de bibliotecas circulantes para a população em geral e de bibliotecas infantis em particular.

10. Redução dos impostos municipais, que incidem sobre os artesões, pequenos comerciantes e industriais.

11. Colaboração corajosa no esforço da Democracia Brasileira em prol da extinção de qualquer [sic] discriminações raciais ou antissemitas, por uma orientação imigratória isenta de preconceitos raciais ou religiosos, pelo desenvolvimento da vida cultural judaica e da solidariedade com o sofredor povo judeu, dentro dos marcos da civilização da Terra Brasileira.

Nossa Voz, São Paulo, 16 de outubro de 1947, n. 29, p. 8. BDLB, acesso em 16 abr 2017. Nossa Voz, São paulo, 23 de outubro de 1947, n. 30, p. 2. BDLB, acesso em 16 abr 2017. 
12. Pela independência e progresso do Brasil, contra a reação, o fascismo e o perigo de guerra, pela Democracia e Paz Mundial. ${ }^{51}$

O penúltimo ponto chama a atenção para o combate ao antissemitismo, algo caro para Elisa e sua comunidade e que não necessariamente constituía um ponto específico do Partido, o que indica certa autonomia dessa - e possivelmente de outras candidaturas. Convém atentar, ainda, para os pontos de forma pormenorizada, uma vez que expressam como os diversos pertencimentos de Elisa se articularam em sua candidatura. Há diretrizes gerais do PCB implícitas (3 e 5, por exemplo), mas no geral é possível perceber a autoria de Elisa. Há questões ligadas ao seu bairro, à preocupação com crianças e com a educação (ela propõe justamente o que viria a ser o Scholem, dois anos depois), a luta contra o antissemitismo e a criação de bibliotecas. ${ }^{52}$

Ao analisar a relação entre mulheres e PCB, Rachel Soihet (2013, p. 173) aponta uma ambiguidade:

Por um lado, acentuavam a necessidade de fazê-las participar de forma mais incisiva das atividades partidárias, [...]. Por outro lado, o movimento comunista oficial reservava às mulheres um papel subalterno, excluídas das funções politicamente mais relevantes, de maior poder decisório [...].

Elisabeth Souza Lobo analisa de forma igualmente crítica a participação das mulheres nas lutas políticas do PCB. Ao estudar as diferentes associações e federações de mulheres que surgiram no período, ${ }^{53}$ a autora afirma:

Os programas das associações e da Federação centraram suas lutas nos bairros, para resolver os problemas locais; pela paz; contra a elevação do custo de vida; pelos direitos da mulher; pela defesa e proteção à infância. Essas lutas, embora representassem uma movimentação ativa, inseriam as mulheres fundamentalmente como colaboradoras das grandes causas nacionais, definidas de modo externo à vivência particular feminina e segundo a lógica da política estatal. [...] Embora tais temas pudessem, em princípio, abrir possibilidades para a participação de mulheres diversas, eles foram instrumentalizados na luta política definida segundo a lógica partidária (LOBO, 2012, p. 212).

Embora a síntese de Lobo e a advertência de Soihet sobre tais movimentos sejam importantes, uma abordagem biográfica permite matizar algumas dessas constatações sempre levando em consideração as relações de poder assimétricas no interior do

51 Nossa Voz, São Paulo, 30 de outubro de 1947, n. 31, p. 8. BDLB, acesso em 16 abr 2017.

52 Dez anos depois a OFIDAS anunciou a criação de sua primeira biblioteca infanto-juvenil, talvez com a ajuda e/ou inspirada em ideias de Elisa. Cf. Nossa Voz, São Paulo, 12 de março de 1957, n. 638, p. 5. BDLB, acesso em 17 abr 2017.

53 Sobre o tema, ver também NUNES, 2018. 
Partido. No caso da campanha e das propostas de Elisa é preciso destacar que pautas e lutas que marcaram sua vida até então estavam em pé de igualdade com as linhas do Partido. Se há uma defesa da paz e da democracia e melhora dos bairros (função de uma vereadora, afinal), há também a defesa da criação de parques, escolas e bibliotecas infantis. Assim, cabe a provocação: será que não devemos inverter a afirmação de Lobo? A saber: embora tais temas pudessem, em princípio, ser instrumentalizados na luta política definida segundo a lógica partidária, eles abriram possibilidades para a participação de mulheres. Não por benevolência da direção partidária, mas justamente pela atuação de Elisa e outras mulheres ao longo do período.

Voltando às propostas de Elisa, o ponto 2 ("remoção do meretrício") aponta os limites da época - e até mesmo atuais - para tratar do tema da prostituição. As mulheres, por sua vez, eram quase sempre acompanhadas dos adjetivos "laboriosas" ou "trabalhadoras". Assim, a forma encontrada para combater a desigualdade entre homens e mulheres seria através do trabalho e da autonomia financeira, diferente do que pregavam outros movimentos de mulheres daquele período. $\mathrm{Na}$ obra Emancipação do Sexo Feminino, por exemplo, June Hahner destaca que "As primeiras defensoras dos direitos da mulher no Brasil viam a educação como uma chave para a emancipação feminina e a melhoria de status." ${ }^{54}$ Elisa foi evidentemente uma militante da educação, mas ela visava às crianças e estava quase sempre ligada a uma perspectiva de classe (crianças necessitadas) ou étnica (judias); não havia, portanto, uma preocupação específica com a educação das mulheres: a chave para a sua emancipação ou melhoria de vida passava sempre pelo trabalho. Evidentemente esse recorte não se deu de maneira tão mecânica e automática. Algumas páginas atrás, inclusive, sugerimos que é provável que Elisa percebesse sim o magistério e a educação como importantes meios de ascensão para as mulheres.

Este não foi, porém, o tom de sua campanha, a qual foi vitoriosa. ${ }^{55} \quad$ Uma semana depois, em 21 de novembro, o jornal Momento Feminino - periódico do PCB feito exclusivamente por mulheres - publicava uma entrevista de página inteira com Elisa, celebrada como "a candidata mais votada em São Paulo". Recebendo a reportagem em seu apartamento no Bom Retiro, a "Elisa Vermelhinha" - apelido que

\footnotetext{
54 HAHNER, June. Emancipação do Sexo Feminino. A luta pelos direitos da mulher no Brasil, 18501940. Santa Cruz: Edunisc; Florianópolis: Editora Mulheres, 2003, p. 115.

55 Nossa Voz, São Paulo, 13 de novembro de 1947, n. 44, p. 8. BDLB, acesso em 16 abr 2017.
} 
remete a seu cabelo ruivo e ao comunismo - contava sobre as dificuldades de se fazer uma campanha, ainda mais na condição de mulher:

\begin{abstract}
Quando meu nome foi indicado para chapa do PST, pensei logo nas imensas dificuldades e na responsabilidade que me cabia. Eu sou mulher, e a campanha eleitoral é dura. A princípio o trabalho estava fraco. Mas depois ficamos nos animando. Organizamos 6 comissões de candidaturas formadas por jovens e mais 6 comissões femininas. Imagine você que fizemos 1.600 visitas domiciliares, apresentando o meu programa mínimo para a Câmara Municipal de São Paulo. Organizamos um churrasco, um baile, festinhas domiciliares, enfim... Tudo o que foi possível..$^{56}$
\end{abstract}

No dia 22 de novembro de 1947, o Jornal de Notícias, veículo paulistano, anunciava em sua capa: "um terço do plenário será composto de vereadores comunistas." O PST fora o mais votado dos partidos, com 72.985 votos, seguido pelo PSP de Ademar de Barros, com 66.829. Elisa computou 2.940 votos, sendo a mulher mais votada e a única eleita no pleito, cabendo-lhe ocupar uma das 15 cadeiras conquistadas pela legenda. ${ }^{57}$

A alegria, porém, durou muito pouco. Embasado nos relatórios do DOPS, o Tribunal Regional Eleitoral de São Paulo cassou todas as candidaturas do PST, alegando tratar-se de uma legenda que abrigava comunistas. Elisa e seus colegas nunca chegaram a tomar posse. ${ }^{58}$ Alguns de seus correligionários, inclusive, chegaram a ser presos..$^{59}$

O clima na imprensa do Partido era de revolta e impotência em 1948, ${ }^{60}$ contrastando com a serenidade de Fanny, em 1997. A filha de Elisa não lamenta o ocorrido, chegando a afirmar que sua mãe teria sido uma "catástrofe" como vereadora: “eu acho que a lei não era o forte dela, a burocracia não era o forte dela, eu não acredito que ela tivesse sido uma boa vereadora, talvez ela tivesse... Ela era uma grande agitadora de massas, ela era uma grande política [nesse] sentido...". ${ }^{61}$

56 O Momento Feminino. Rio de Janeiro, 21 de novembro de 1947, p. 4. HD/BN, acesso em 30 abr 2017.

57 Jornal de Notícias, São Paulo, 22 de novembro de 1947, ano II, n. 488, p. 1. HD/BN, acesso em 10 mai 2018. Para fins de comparação, o candidato mais votado da sigla, Mário de Souza Sanches, fez 5.804 votos, e o mais votado de todo o pleito, José Adriano Marrey Júnior, do PSP, fez 7.258.

58 Nesse mesmo pleito o município de Santo André elegeu o primeiro prefeito de origem operária da história do Brasil, o comunista - e igualmente abrigado no PST - Armando Mazzo, que também não chegou a tomar posse. Ver NEGRO, Antônio Luigi; SILVA, Fernando Teixeira Da. Trabalhadores, Sindicato e Política (1945-1964). In FERREIRA, Jorge; DELGADO, Lucilia de Almeida Neves (orgs.). O Brasil Republicano 3: o tempo da experiência democrática. $5^{\text {a }}$ edição - Rio de Janeiro: Civilização Brasileira, 2013, p. 60.

59 A Classe Operária, n. 103, 09 de dezembro de 1947, p. 8. CEDEM/UNESP.

60 A Classe Operária. n. 107, 07 de janeiro de 1948, p. 2. CEDEM/UNESP.

61 Entrevista de Fanny Abramovich a Sara Altman em 20/04/1997, p. 17. Núcleo de História Oral Gaby Becker, AHJB. 
O DOPS também percebia Elisa como uma grande liderança e agitadora, mas sobretudo nos bastidores, onde poderia lançar mão de sua discrição - diferindo, portanto, da ideia de "agitadora de massas". Sua campanha a colocou na mira da vigilância e, em 1949, uma investigação afirmava que Elisa participava da Associação Cívica Feminina do Bom Retiro, frequentada por "simpatizantes do credo vermelho". ${ }^{6}$ Nesse mesmo ano o DOPS descreve um genérico "departamento feminino" do PCB, responsável por organizar a campanha pela paz e pela baixa dos preços dos gêneros alimentícios e que funcionaria "sob orientação direta, segundo consta, da ex-candidata Elisa Kaufmann."

À medida que o Scholem Aleichem e a colônia de férias da AFIB emplacavam e exigiam grande dedicação de Elisa, sua militância no PC parece ter diminuído - embora nunca se encerrado. $\mathrm{Na}$ imprensa partidária seu nome desaparece, assim como na documentação do DOPS. Em Nossa Voz, foram encontradas apenas duas menções às suas atividades políticas, quase sempre como signatária de algum manifesto em favor de algum candidato.

\section{Considerações finais}

Elisa faleceu no início de 1963 e os escritos que surgem a partir daí também são muito ilustrativos acerca de como se enquadrou uma memória sobre ela a partir desse triste acontecimento. Elisa é enaltecida como "destacada dirigente cultural-social e diretora da Escola", e não como mãe, filha ou esposa. Em sua morte, foi mais lembrada pela sua atuação no espaço público, e praticamente todas as entidades nas quais militou prestam a ela sua homenagem. Essa celebração póstuma também foi noticiada pelo jornal Nossa Voz:

[...] Essa reunião de homenagem póstuma, que lotou inteiramente a sala de espetáculos do TAIB, foi promovida pela Escola Israelita Brasileira "Scholem Aleichem", em conjunto com o Instituto Cultural Israelita Brasileiro, Associação Feminina Israelita Brasileira, Nossa Voz, Clube Infanto-Juvenil "I. L. Peretz", União dos Israelitas Poloneses e Comitê Icuf de São Paulo, contando ainda com a adesão da Associação Brasileira "A Hebraica" de S. Paulo.

$[\ldots]$

62 Secretaria da Segurança Pública. Departamento de Ordem Política e Social. Investigação $N^{\circ} 169$, 7/03/1949. APESP. Dossiê Comunismo, OS 1913, pasta 12, p. 316.

63 Secretaria da Segurança Pública. Departamento de Ordem Política e Social. Documento avulso. Informação reservada. APESP. Dossiê Comunismo, OS 1915, pasta 14, p. 274. 
Todas as instituições e organizações atingidas pela rude perda o sentem profundamente. Mas a memória de Elisa Kauffmann Abramovich servirá de inspiração em todos os lugares em que atuou. Seu nome, que não será esquecido, é uma bandeira para a sociedade judaica progressista, para todos que lutam por um mundo de paz e justiça social. ${ }^{64}$

De certa forma, a última imagem que fica enquadrada de Elisa é como sendo "uma bandeira para a sociedade judaica progressista." Sandra Deutsch, ao estudar mulheres judias na Comissão Feminina do ICUF argentino, afirma que, ao trazerem questões discutidas nessas organizações, elas puderam incrementar a estratégia do PC argentino entre as mulheres. Dessa forma, elas "não precisaram escolher entre uma identidade comunista ou judaica, puderam ter as duas."65 Tal noção parece se aplicar também ao caso de Elisa, que teve esses dois pertencimentos fortemente vinculados entre si, um reforçando o outro.

Fanny, aliás, elaborou uma espécie de síntese de suas memórias acerca de Elisa, bastante adequada para essa parte final do capítulo:

[...] tão, dona do seu nariz e do que queria e do que pensava que, quando ela morreu, ela teve um câncer sério, sofrido, ficou um ano na químio, na rádio, essa coisa toda. Isso foi de 1962 para 1963, e quando ela faleceu, nós descobrimos lá no diário dela, e no diário dela tinham as deliberações de como ela queria o enterro, e ela queria que no enterro o Maurício Segall, que ela tinha recrutado para ser do Partido Comunista que tinha saído, falasse em nome do partido. Ela ainda recrutou gente sendo encaixada, sendo enterrada. E houve, e eu me lembro até hoje do Maurício na minha casa, na Rua Prates, passando a noite porque a mamãe morreu em uma sexta, e dizem que os justos morrem em uma sexta para serem enterrados no domingo e terem mais tempo de serem velados, ela e o titio morreram em uma sexta, e então o que passou de gente que dizia 'morreu a minha mãe', e eu dizia 'Meu Deus, não, foi a minha mãe", [risos] não é? [...] no dia do enterro o Prestes falou, ele veio, no enterro tinham 10 mil pessoas, nunca se viu coisa igual para aquela época, mas quem falou oficialmente do partido foi o Maurício Segall. ${ }^{66}$

Elisa seria uma figura tão organizada - e organizadora - e tão disciplinada, tão devotada ao Partido, que conseguiu militar e recrutar novos integrantes mesmo depois de morta.

64 Nossa Voz, São Paulo, 7 de fevereiro de 1963, n. 965, p. 1. HDB/BN, acesso em 17 abr 2017.

65 DEUTSCH, Op. cit., p. 173. Tradução minha, no original: "Women did not have to choose a Jewish or Communist identity; they could have both."

66 Entrevista de Fanny Abramovich a Sara Altman em 20/04/1997, p. 22-23. Núcleo de História Oral Gaby Becker, AHJB. 


\section{Bibliografia}

ABRAMOVICH, Fanny. In: CHARNIS, Cristina Catalina et all. A VANGUARDA PEDAGÓGICA: o legado do Colégio Israelita Scholem Aleichem. São Paulo: Lettera.doc, 2008.

ALMEIDA, Natália Frizzo de. Memória, História e Renovação Pedagógica O Ginásio Israelita Brasileiro Scholem Aleichem. Dissertação (Mestrado em Educação). São Paulo: USP, 2015.

AJZENBERG, Marcos. In: CHARNIS, Cristina Catalina et all. A VANGUARDA PEDAGÓGICA: o legado do Colégio Israelita Scholem Aleichem. São Paulo: Lettera.doc, 2008.

ALTMAN, Max. In: CHARNIS, Cristina Catalina et all. A VANGUARDA PEDAGÓGICA: o legado do Colégio Israelita Scholem Aleichem. São Paulo: Lettera.doc, 2008.

CARNEIRO, Maria L. T. A Imagem do Imigrante Indesejável. Seminários, São Paulo, v. 3, n. 3, Dezembro, p. 21-42, 2003.

CYTRYNOWICZ, Rony. Beyond the Stante and Ideology: Imigration of the Jewish Community ti Brail, 1937-1945. In LESSER, Jeffrey; REIN, Raanan. Rethinking Jewish-Latin Americans. Albuquerque: University of New Mexico Press, 2008.

DEUTSCH, Sandra Magee. Changing the Landscape. The Study of Argentine-Jewish Women and New Historical Vistas. In LESSER, Jeffrey; REIN, Raanan. Rethinking Jewish-Latin Americans. Albuquerque: University of New Mexico Press, 2008.

DEUTSCHER, Isaac. Quem é Judeu? In: O Judeu Não-Judeu e outros ensaios. Rio de Janeiro: Civilização Brasileira, 1970.

FERREIRA, A. S.; LINS, M. S. As Questões de Gênero no interior do Partido Comunista do Brasil - PCB (1922-1947). Temporalidades, v. 7, p. 176-190, 2015. 
FILHO, Fausto Salvadori. Ela não teve medo da vida. In Revista Apartes, março-abril de 2014.

GOLDFELD, Monique Sochaczevski. Senhoras Progressistas e uma terra de crianças: a história da Associação Feminina Israelita Brasileira (1947) e da Colônia de Férias Kinderland (1952). Rio de Janeiro: edição da autora, 2007.

GUY, Donna J. Women's Organization and Jewish Orphanages in Buenos Aires, 19181955. In LESSER, Jeffrey; REIN, Raanan. Rethinking Jewish-Latin Americans. Albuquerque: University of New Mexico Press, 2008.

HAHNER, June E. Emancipação do Sexo Feminino. A luta pelos direitos da mulher no Brasil, 1850-1940. Santa Cruz: Edunisc; Florianópolis: Editora Mulheres, 2003.

HALL, Michael M. Entre a etnicidade e a classe em São Paulo. In CARNEIRO, Maria L. T.; FRANZINA, Frederico C. E. História do Trabalho e Histórias da Imigração. São Paulo: EDUSP/FAPESP, 2010.

IOKOI, Zilda Márcia Grícoli. Intolerância e resistência. A saga dos judeus comunistas entre a Polônia, a Palestina e o Brasil (1935-1975). São Paulo: Associação Humanitas; Itajaí: Ed. Univali, 2004.

LEVI, Giovanni. Usos da biografia. In: AMADO, Janaína e FERREIRA, Marieta de Moraes (orgs.). Usos \& abusos da história oral. Rio de Janeiro: Ed. FGV, 1996.

LOBO, Elisabeth Souza. A classe operária tem dois sexos. Trabalho, Dominação e Resistência. São Paulo: Brasiliense, 1991, p. 211-216, In LÖWY, Michael (Org.). $O$ marxismo na América Latina: uma antologia de 1909 aos dias atuais. São Paulo: Fundação Perseu Abramo, 2012.

LOURO, Guacira Lopes. Mulheres na Sala de Aula. In: DEL PRIORE, Mary; BASSANEZI (Orgs.). História das Mulheres no Brasil. São Paulo: Contexto, 1997. 
LUEDDEMANN, Cecília. In: CHARNIS, Cristina Catalina et all. A VANGUARDA PEDAGÓGICA: o legado do Colégio Israelita Scholem Aleichem. São Paulo: Lettera.doc, 2008.

MARTINS, Ana Paula Vosne. A Feminilização da Filantropia. Gênero, Niterói, v. 15, n.2, p. 13-28, 2015.

MELO, Hildete Pereira de; RODRIGUES, C. La trajectoria de las mujeres comunistas brasilenas: una historia sin contar. In: Adriana Valobra; y Mercedes Yusta. (Org.). Queridas Camaradas - Historias iberoamericanas de mujeres comunistas. Buenos Aires: Mino y Dávila Editores, v. 1, p. 91-112, 2017.

NUNES, Guilherme Machado. União Nacional, sindical e continental: aproximações entre PCB e CTAL e o caso das Uniões Femininas no Brasil nos anos 1940. In: Norberto Ferreras, Andrés Stagnaro e Laura Caruso. (Org.). A Conexão OIT: problemas regionais do trabalho em perspectiva transnacional. 1ed.Rio de Janeiro: Mauad X, 2018, v. 1, p. $123-140$.

STAROBINAS, Lilian. ABRAMOVICH, Fanny. In: CHARNIS, Cristina Catalina et all. A VANGUARDA PEDAGÓGICA: o legado do Colégio Israelita Scholem Aleichem. São Paulo: Lettera.doc, 2008.

O PCB e sua atuação nos anos 50: Waldir José Rampinelli entrevista Jacob Gorender. Rev. Bras. Hist.[online]. vol.23, n.45 pp.303-309.

PERROT, Michelle. Minha História das Mulheres. São Paulo: Contexto, 2012.

Os Excluídos da História: operários, mulheres e prisioneiros. São Paulo: Paz e Terra, 2006.

Práticas de memória feminina. Revista Brasileira de História. São Paulo, vol. 9, n. 18, ago-set., pp. 9-18, 1989. 
QUADROS, Carlos Fernando de. Jacob Gorender, um militante comunista: estudo de uma trajetória política e intelectual no marxismo brasileiro (1923-1970). Dissertação (Mestrado em História), Universidade de São Paulo: São Paulo, 2015.

SOIHET, Rachel. Do Comunismo ao Feminismo: a trajetória de Zuleika Alambert. Cadernos Pagu (UNICAMP. Impresso), v. 40, p. 1-195, 2013.

VELHO, Gilberto. Projeto e metamorfose. Antropologia das sociedades complexas. RJ: Zahar, 1999.

ZEN, Erick R. G. Imigração e Revolução: lituanos, poloneses e russos sob vigilância do DEOPS. São Paulo: EDUSP, 2010. 